\title{
Chapter 11 \\ In Situ Environmental Radioactivity \\ Measurement in High-Dose Rate Areas Using \\ a CdZnTe Semiconductor Detector
}

\author{
Munehiko Kowatari, Takumi Kubota, Yuji Shibahara, Toshiyuki Fujii, \\ Koichi Takamiya, Satoru Mizuno, and Hajimu Yamana
}

\begin{abstract}
For the purpose of determining a surface deposition density on soil for radio-cesiums, a CdZnTe (CZT) semiconductor detector whose crystal has dimensions of $1 \mathrm{~cm}$ cubic was applied to the in situ environmental radioactivity measurement in deeply contaminated areas in Fukushima region. Even in highdose rate areas where pulse height spectra weren't able to be properly obtained by the conventional high-purity $\mathrm{Ge}(\mathrm{Hp}-\mathrm{Ge})$ semiconductor detector, proper pulse height spectra were obtained by the CZT detector with certain accuracy. Results of deposition density on soil for ${ }^{134} \mathrm{Cs}$ and ${ }^{137} \mathrm{Cs}$ derived from net peak areas by the CZT detector seemed consistent, comparing with those measured by the Japanese government. Air kerma rates were estimated by the same pulse height spectra for determining surface deposition density on soil for radio-cesiums. Estimated results showed almost the same values as obtained by the $\mathrm{NaI}(\mathrm{Tl})$ scintillation survey meter. The results indicate that the CZT detector can be applied to rapid and simple in situ gamma ray radioactivity measurement in higher-dose rate areas whose dose rates exceed several tenth $\mu \mathrm{Sv} \mathrm{h}^{-1}$. The study also strongly supports that the CZT detector is one promising candidate for the detector to be used for checking the effect of decontamination works and for long-term monitoring in heavily contaminated areas.
\end{abstract}

Keywords CdZnTe detector • In situ gamma ray environmental measurement • Decontamination $\bullet$ Dose rate $\bullet$ Environmental radiation monitoring $\bullet$ Surface deposition density on soil $\bullet{ }^{137} \mathrm{Cs} \cdot{ }^{134} \mathrm{Cs}$

\footnotetext{
M. Kowatari $(\bowtie)$

Department of Radiation Protection, Nuclear Science Research Institute, Japan Atomic Energy Agency, 2-4 Shirakata, Tokai, Naka, Ibaraki 319-1195, Japan

e-mail: kowatari.munehiko@jaea.go.jp

T. Kubota $\bullet$ Y. Shibahara $\bullet$ T. Fujii $\bullet$ K. Takamiya $\bullet$ H. Yamana

Research Reactor Institute, Kyoto University, Kumatori, Osaka 590-0494, Japan

S. Mizuno

Nuclear Power Safety Division, Fukushima Prefectural Government, Fukushima,

Fukushima 960-8670, Japan
} 


\subsection{Introduction}

After the Fukushima Nuclear Accident, contamination by a vast amount of radioactive materials released due the accident still remains in areas close to the Fukushima Daiichi Nuclear Power Station (FDNPS). Decontamination and remediation works in heavily contaminated areas are recognized a challenging practice. Particularly, methodologies of decontamination and its confirmation of effect in deeply contaminated areas where there are consequently high dose rates have been being intensively developed.

Among methodologies for determining the surface deposition density on soil, in situ environmental gamma ray measurement using high-purity Ge detector $[1,2]$ is widely recognized effective and reliable and has been playing an important role in the measurement campaign in the whole region of northern part of Japan under the conduction of the government of Japan (http://radioactivity.nsr.go.jp/en/). On the other hand, high dose rates more than tenth $\mu S v h^{-1}$ impede the precise spectrometry using the Ge detectors caused by their own high sensitivity to gamma rays. In our measurement campaign for investigating the isotropic ratio of radiocesiums [3, 4], the Ge detector used was not able to show its high energy resolution when measured in higher-dose rate areas. This was caused by broadening each peak in the pulse height spectrum due to overlapping of too many events incoming the detector sensitive region.

Comparing with Ge detectors, a newly developed CdZnTe (CZT) detector has less energy resolution of pulse height spectrum. A CZT detector which has a small detector element is also less sensitive to gamma rays from radio-cesiums. However, a CZT detector has enough energy resolution to distinguish peaks by gamma rays from ${ }^{134} \mathrm{Cs}$ and ${ }^{137} \mathrm{Cs}$ (i.e. its progeny, ${ }^{137 \mathrm{~m}} \mathrm{Ba}$ ). The lower sensitivity to gamma rays would enable us to appropriately measure pulse height spectra in the environment whose dose rates reach more than few tenth $\mu \mathrm{Sv} \mathrm{h}^{-1}$. In addition, a CZT detector is an easy-to-use, light-weight and coolant-free detector. Considering these characteristics, a CZT detector also would help determine environmental radioactivity even in deeply contaminated areas whose dose rates exceed more than a couple of tenth $\mu \mathrm{Sv} \mathrm{h}^{-1}$.

This article describes investigation on the adaptability of a CZT detector to an in situ environmental radioactivity measurement. Before measurements, energy dependence of peak efficiency and angular dependence of peak efficiency for the CZT detector were evaluated. A series of environmental radioactivity measurements were then conducted within the region within several kilometers in radius centering the FDNPS, which is designated as the so-called difficult-to-return zone, which is deeply contaminated areas due to radio-cesiums from the FDNPS. There are still some places whose ambient dose equivalent rates exceed several tenth $\mu \mathrm{Sv} \mathrm{h}^{-1}$ and require to be remediated. Surface contamination densities on soil due to radiocesiums were determined from measured pulse height spectra. Air kerma rates at measurement points were also estimated from the same pulse height spectra 
by means of three methodologies. Measured results were then compared with those obtained by the government of Japan (http://radioactivity.nsr.go.jp/en/). The usability of the CZT was also discussed in this article.

\subsection{Materials and Methods}

In this study, a CZT detector was used as a detector which applies the rapid and simple in situ environmental gamma ray measurement for determining surface deposition on soil due to radio-cesiums. Considering its characteristics of gamma ray detection described above, a CZT detector is taken as one promising candidate for the purpose. In addition, high-dose areas limit remediation and monitoring activities. As summarized in Table 11.1, a light, easy-to-use, USB-powered and coolant-free CZT detector allows us to expand our remediation and monitoring activities. This strongly will promise rapid, safe and efficient monitoring activities for a limited time. Figure 11.1 shows the appearance and cross-sectional drawing for the CZT detector assembly (Kromek GR $1^{\mathrm{TM}}$ ) used in this study. The sensitive region of the detector is made of $\mathrm{CdZnTe}$ semiconductor crystal, and the dimension of the sensitive region is $1 \mathrm{~cm}^{3}$.

Surface deposition densities of radio-cesiums using the CZT detector were measured from 27 to 28 May 2013 and from 11 to 13 December 2013. The CZT detector was set at the height of $1 \mathrm{~m}$, using a conventional tripod. For obtaining pulse height spectra from the CZT detector and for power supply, a laptop PC was connected to the detector by a USB cable. Open and level fields which have no buildings within at least $10 \mathrm{~m}$ from the center of measuring points were selected, as possible. Ambient dose equivalent rates at measurement points were

Table 11.1 Comparison of characteristics of the conventional Ge semiconductor detector and the CZT detector

\begin{tabular}{l|l|l}
\hline & $\begin{array}{l}\text { High purity Ge semiconductor } \\
\text { detector }\end{array}$ & $\begin{array}{l}\text { CdZnTe semiconductor } \\
\text { detector }\end{array}$ \\
\hline Detector element & Ge & CdZnTe \\
\hline $\begin{array}{l}\text { Typical dimension and shape } \\
\text { of detector element }\end{array}$ & Cylindrical $5.0 \mathrm{~cm} \varphi \times 6.0 \mathrm{~cm}^{\mathrm{L}}$ & Cubic $1.0 \times 1.0 \times 1.0 \mathrm{~cm}^{3}$ \\
\hline $\begin{array}{l}\text { Typical energy resolution for } \\
137 \text { Cs: } 662 \mathrm{keV}(\mathrm{FWHM})(\%)\end{array}$ & $0.2 \sim 0.3$ & $2.0 \sim 2.5$ \\
\hline Weight $(\mathrm{kg})$ & $\sim 10$ (including $\left.\mathrm{LN}_{2}\right)$ & 0.05 \\
\hline $\begin{array}{l}\text { Cost }(\text { Japanese yen) (initial, } \\
\text { including measurement } \\
\text { system) }\end{array}$ & $3,000,000 \sim 10,000,000$ & $600,000 \sim 1,000,000$ \\
\hline (running) & $10,000 \sim$ per 1 day & $0 \sim$ \\
\hline Necessary to be cooled & $\begin{array}{l}\text { Yes }(\mathrm{LN} 2 \text { or electric cooling } \\
\text { system) }\end{array}$ & None \\
\hline External power supply & Required & None \\
\hline
\end{tabular}



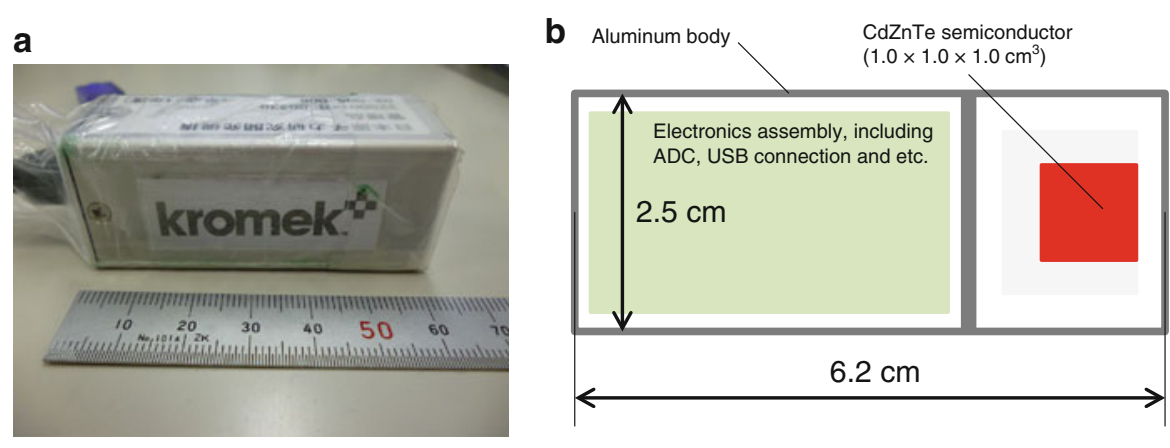

Fig. 11.1 Appearance (a) and cross sectional drawing (b) for the CZT detector assembly (Kromek $\mathrm{GR} 1^{\mathrm{TM}}$ )

also monitored using the $\mathrm{NaI}(\mathrm{Tl})$ scintillation survey meter and ranging between 0.2 and $45 \mu \mathrm{Sv} \mathrm{h}^{-1}$. Measurement time for each point changed according to the dose rates and was set to $600 \mathrm{~s}$ for high-dose rate areas and $1200 \mathrm{~s}$ for lower-dose rate areas, respectively.

Surface deposition densities on soil of each radio-cesium $\mathrm{A}_{\mathrm{a}}\left(\mathrm{kBq} \mathrm{m}^{-2}\right)$ were determined by dividing peak areas per second $\mathrm{N}_{\mathrm{f}}$ (cps) due to gamma rays from ${ }^{134} \mathrm{Cs}$ and ${ }^{137} \mathrm{Cs}$ by peak efficiencies with energies of gamma rays, $\mathrm{P}_{\text {eff }}$ (cps $\left.\left(\mathrm{kBq} \mathrm{m}^{-2}\right)^{-1}\right)$. Equation (11.1) shows the surface deposition density on soil, $\mathrm{A}_{\mathrm{a}}$ :

$$
A_{a}=\frac{N_{f}}{\mathrm{P}_{\mathrm{eff}}}
$$

The peak efficiency, $\mathrm{P}_{\text {eff }}$, for an incident gamma ray with energy of $\mathrm{E}(\mathrm{keV})$ was derived in accordance with Eq. (11.2):

$$
\mathrm{P}_{\mathrm{eff}}=\frac{N_{0}}{\phi} \frac{N_{f}}{N_{0}} \frac{\phi}{A_{a}}
$$

where $\mathrm{N}_{0} / \varphi$ is a net peak area for full energy absorption of incident gamma ray per unit gamma ray fluence. $\mathrm{N}_{0} / \varphi$, was then obtained by measuring pulse height spectra using checking radioactive sources such as ${ }^{152} \mathrm{Eu},{ }^{60} \mathrm{Co}$ and ${ }^{137} \mathrm{Cs}$ and by calculating using the EGS4 Monte Carlo code. $\mathrm{N}_{\mathrm{f}} / \mathrm{N}_{0}$ is the correction factor for angular dependence of a net peak area for full energy absorption of the CZT detector used. $\varphi / \mathrm{A}_{\mathrm{a}}\left(\left(\mathrm{cm}^{-2} \mathrm{~s}^{-1}\right)\left(\mathrm{kBq} \mathrm{m}^{-2}\right)^{-1}\right)$ is a gamma ray fluence rate at $1 \mathrm{~m}$ above the ground per unit surface deposition density of each radionuclide of interest, namely, ${ }^{134} \mathrm{Cs}$ and ${ }^{137} \mathrm{Cs}$. This depends on the migration of soil from the surface of ground, and depth profile of concentration of radionuclides in soil varies as time elapses from the initial deposition. The parameter defined as a relaxation mass per unit area, $\beta\left(\mathrm{g} \mathrm{cm}^{-2}\right)$, is used to express the vertical distribution of radionuclides deep inside soil $[1,2]$. In this study, $\beta$ was set to 2 and/or 3 , in accordance with the 
recommendation of reference 2 . The reference 2 explains the effect of attenuation of gamma rays due to surface soil and migration of radio nuclides on soil according to the time elapsed from initial deposition of radionuclides to the measurement date in detail.

Air kerma rates at measurement points were estimated from measured surface contamination densities on soil by the CZT detector. In addition, using the same spectra obtained by the CZT detector, air kerma rates at measurement places were estimated by the stripping method [5] and the G(E) function method [6]. Evaluating dose rate using the same pulse height spectra would enhance information on measurement points, help shorten staying time in higher-dose rate areas and facilitate a long-term monitoring of heavily contaminated areas. Regarding the stripping method, the response matrix of the CZT detector to mono-energetic gamma rays ranging from $50 \mathrm{keV}$ to $3 \mathrm{MeV}$ was calculated by MCNP-4C code. The pulse height spectrum was decomposed to gamma ray fluence spectrum by applying calculated response matrix. The air kerma rate was then estimated by multiplying fluence-to-air-kerma conversion coefficient taken from ICRP 74 [7] with obtained gamma ray fluence. In contrast, the $G(E)$ function method enables us to directly determine air kerma rates from the accumulated pulse height spectra, by employing the operator defined, "G(E) function." The method has also taken advantage of direct determination of air kerma rates which the effect of scattered gamma ray components is included. The previous literature gives more detailed explanations on the $\mathrm{G}(\mathrm{E})$ function method and its application to environmental radiation measurement [6]. The $\mathrm{G}(\mathrm{E})$ function for the CZT detector was derived from the calculated responses matrix of the CZT detector to mono-energetic gamma rays ranging from $50 \mathrm{keV}$ to $3 \mathrm{MeV}$. The EGS4 was used for the calculation. Before determining air kerma rates by pulse height spectra obtained in the field, the calculated response functions were verified by comparing the measured spectra from point sources of ${ }^{137} \mathrm{Cs}$ with the calculated spectra.

\subsection{Results and Discussion}

As basic characteristics of the detectors for in situ environmental radioactivity measurement, energy and angular dependences of full energy absorption peak efficiency of the CZT detector were evaluated. Figure 11.2 shows measured and calculated peak area per unit gamma ray fluence as a function of gamma ray energy. In the energy region around $100 \mathrm{keV}$, peak efficiency reaches up to almost 0.9 . On the other hand, quite low values with energies more than around $1500 \mathrm{keV}$ suggest that the CZT detector has less sensitivity to energetic gamma ray from ${ }^{40} \mathrm{~K}$ and/or ${ }^{208} \mathrm{Tl}$. Figure 11.3 shows the angular dependence of a relative net peak area for full energy absorption as a function of incident gamma ray energy. In this figure, $0^{\circ}$ corresponds to a direction of the detector axis, and $90^{\circ}$ is a horizontal direction to the ground. Values in the Fig. 11.3 were normalized by those obtained at $90^{\circ}$. Figure 11.3 indicates that calculated net peak areas for incident gamma rays 


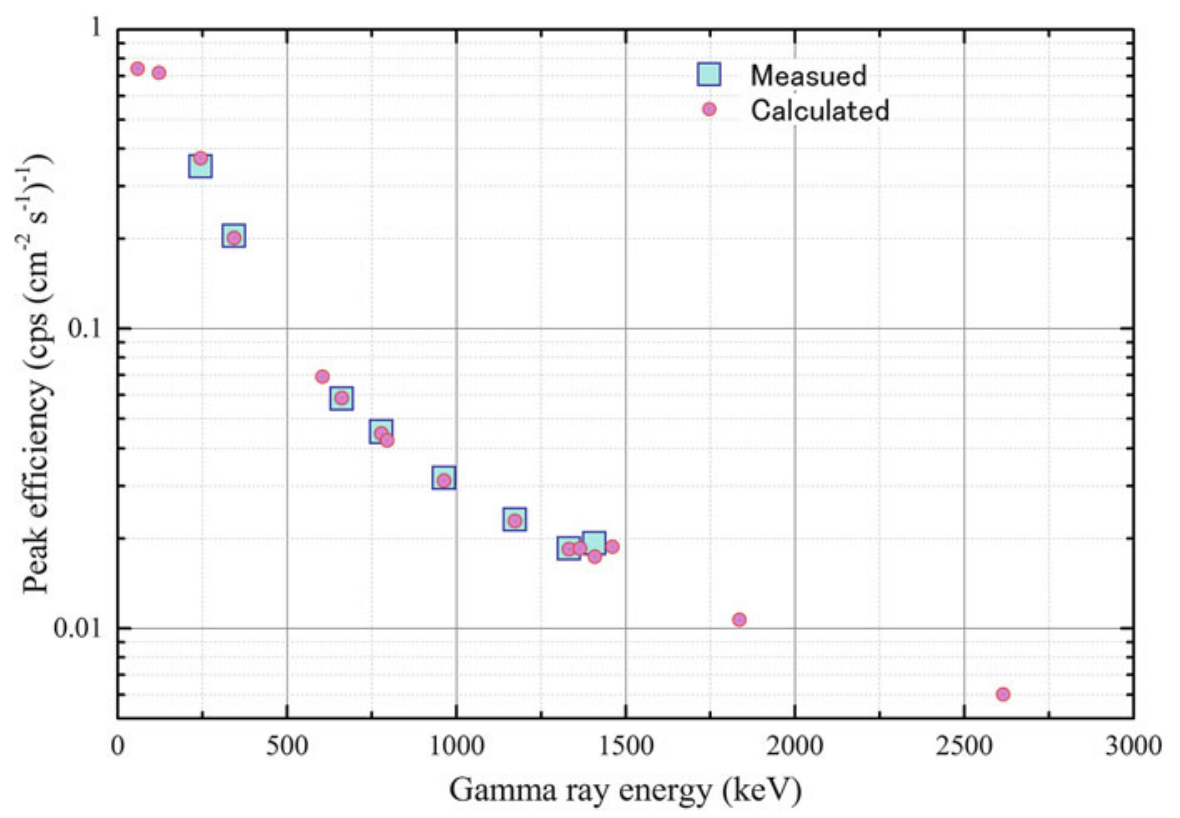

Fig. 11.2 Measured and calculated full energy absorption peak efficiency of the CZT detector

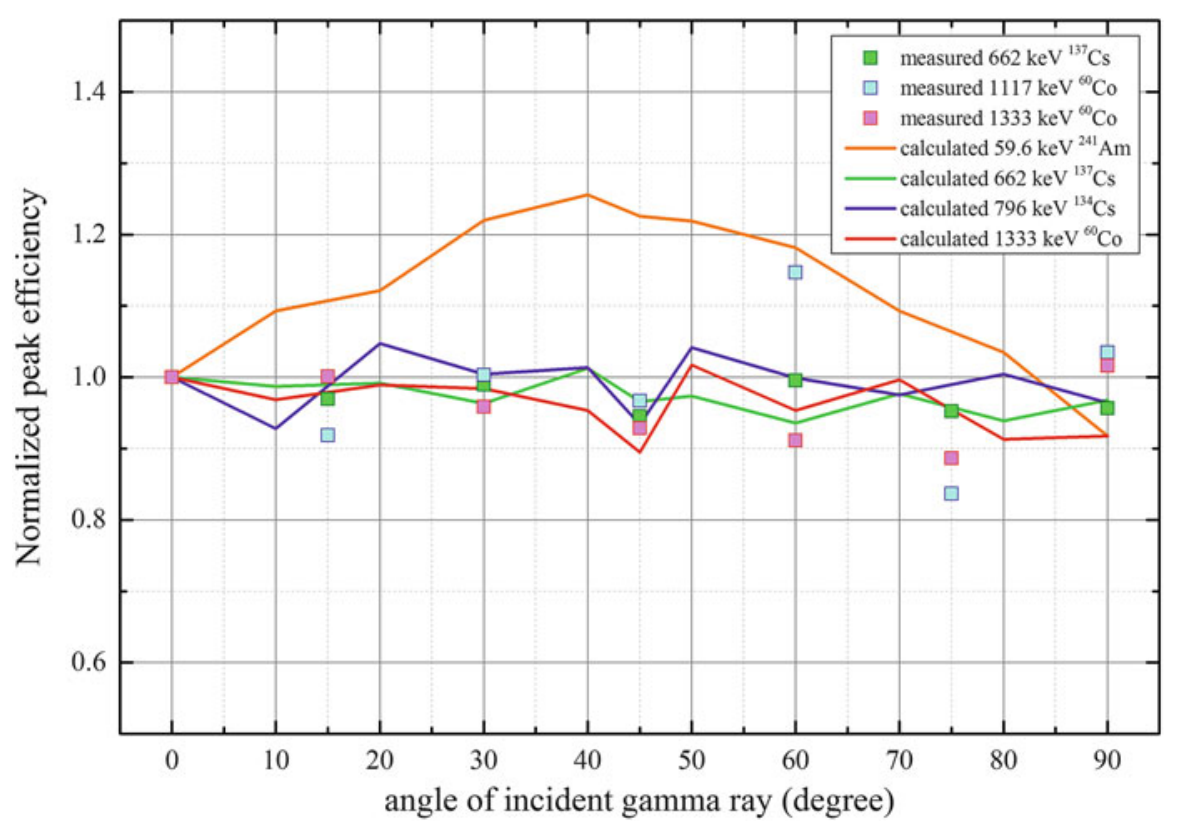

Fig. 11.3 Angular dependence of full energy peak efficiency of the CZT detector as a function of incident gamma ray energy 


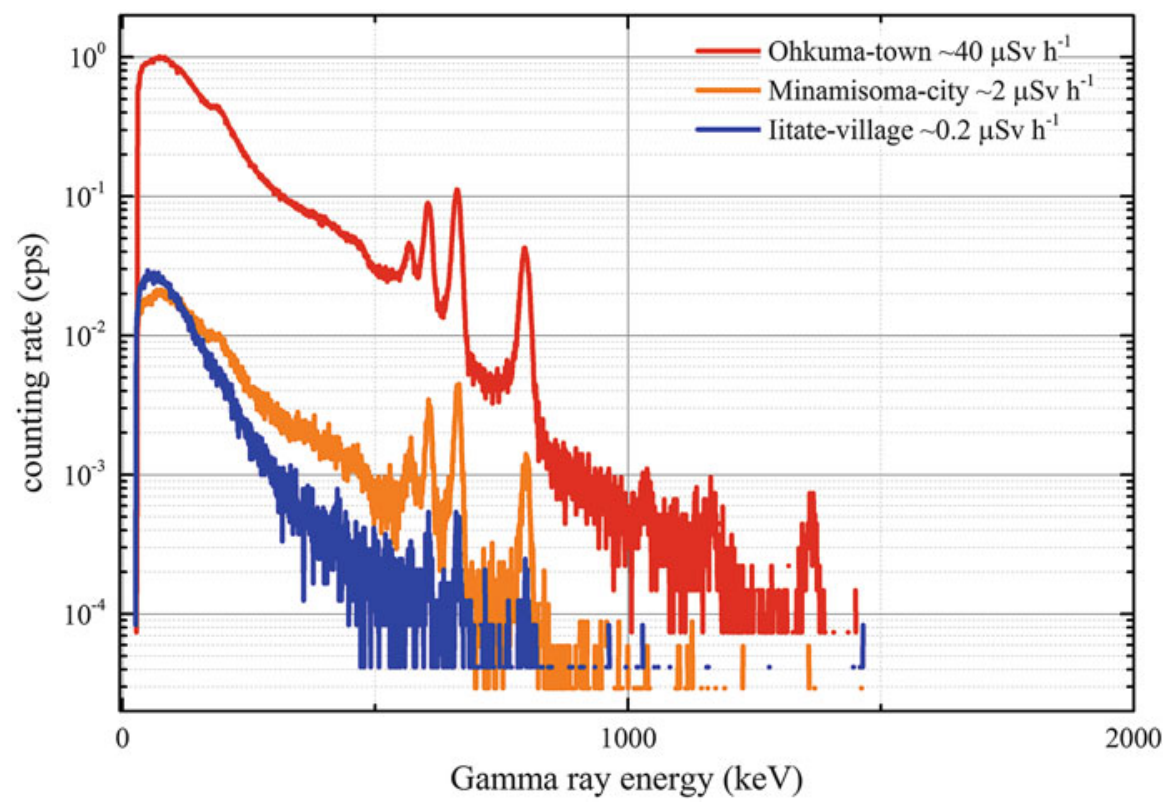

Fig. 11.4 Comparison of pulse height spectra from the CZT detector obtained in areas whose dose rates range between 0.2 and $40 \mu \mathrm{Sv} \mathrm{h}^{-1}$

with energies between 662 and $1333 \mathrm{keV}$ was evaluated to be within $10 \%$ of those obtained at $90^{\circ}$ by Monte Carlo calculations using MCNP-4C. Measured results were also found to be within $20 \%$ of those obtained at $90^{\circ}$. This shows that the CZT detector has less angular dependence to gamma rays with energies between 662 and $1333 \mathrm{keV}$. From measured and calculated results, values of $\mathrm{N}_{\mathrm{f}} / \mathrm{N}_{0}$ for ${ }^{134} \mathrm{Cs}$ and ${ }^{137} \mathrm{Cs}$ gamma rays were both taken as 1.0. Results shown in Figs. 11.1 and 11.2 imply that the CZT detector could allow us to properly measure pulse height spectra in heavily contaminated areas.

In situ environmental radioactivity measurements using the CZT detector were made inside the difficult-to-return zone at several kilometers from the FDNPS and also within $40 \mathrm{~km}$ in radius centering the FDNPS. Figure 11.4 shows examples of pulse height spectra obtained in areas whose ambient dose equivalent rates range from 0.2 to $45 \mu \mathrm{Sv} \mathrm{h}^{-1}$. Pulse height spectrum was obtained in $600 \mathrm{~s}$ at measurement point whose dose rate was monitored to be $45 \mu \mathrm{Sv} \mathrm{h}^{-1}$. As shown in Fig. 11.4, peaks due to gamma rays from radio-cesiums were clearly identified. The dead time observed in the area whose dose rate was around $40 \mu \mathrm{Sv} \mathrm{h}^{-1}$ was around $1 \%$, and this would lead to the proper measurement for determining on surface deposition density on soil of radio-cesiums. Peaks due to gamma rays from ${ }^{40} \mathrm{~K}$, however, could not be seen in each pulse height spectrum. As shown in Fig. 11.1, the CZT detector has less sensitivity to energetic gamma rays more than around $1500 \mathrm{keV}$, comparing 
those from ${ }^{137} \mathrm{Cs}$. The CZT detector was not able to observe events enough to form the peak due to gamma rays with energy of $1460 \mathrm{keV}$ from ${ }^{40} \mathrm{~K}$.

This might also be rather advantageous, if the detector were to be used for confirming the effect of the decontamination work in higher-dose rate regions. It would be a crucial disadvantage that the CZT detector could not clearly identify peaks due to gamma rays from ${ }^{40} \mathrm{~K}$ in the case of general environmental radioactivity measurement. On the other hand, gamma rays emitted from ${ }^{134} \mathrm{Cs}$ and ${ }^{137} \mathrm{Cs}$ have been still contributing to high dose rate in the "difficult-to-return areas." Considering that gamma rays emitted by these contaminants should be well identified, the effect of higher-energy gamma rays from ${ }^{40} \mathrm{~K}$ is properly eliminated from pulse height spectra obtained by the CZT detector. From this viewpoint, the CZT detector enables to easily confirm the effect of decontamination work with certain accuracy.

Measured surface deposition densities on soil of ${ }^{134} \mathrm{Cs}$ and ${ }^{137} \mathrm{Cs}$ were summarized in Table 11.2, derived from net peak areas in pulse height spectra and calculated in accordance with Eq. (11.1). All the results in Table 11.2 were corrected to the date of the initial deposition (11 March 2011), by applying half-life of ${ }^{134} \mathrm{Cs}$ (2.0684 y) and ${ }^{137} \mathrm{Cs}(30.167 \mathrm{y})$. In addition to the surface deposition density on soil, air kerma rates due to radio-cesiums at measurement date were estimated from measured results and also listed in the table. Measured results seemed consistent, comparing with those evaluated by the measurement campaign by the government of Japan (http://radioactivity.nsr.go.jp/en/). Results obtained in wider regions are also summarized in our previous report [4].

Table 11.2 Comparison of surface deposition densities on soil within $7 \mathrm{~km}$ in radius centering the FDNPS. Measurement was conducted from 27th May 2013 to 28th May 2013

\begin{tabular}{|c|c|c|c|c|c|}
\hline \multirow[b]{2}{*}{ Location } & \multirow[b]{2}{*}{$\begin{array}{l}\text { Coordinate } \\
\text { of } \\
\text { location }\end{array}$} & \multirow[b]{2}{*}{$\begin{array}{l}\text { Distance } \\
\text { from } \\
\text { FDNPS } \\
(\mathrm{km})\end{array}$} & \multicolumn{2}{|c|}{\begin{tabular}{|l|}
$\begin{array}{l}\text { Measured surface deposition density on } \\
\text { soil at 11th March, } 2011\left(\mathrm{kBq} \mathrm{m}^{-2}\right)\end{array}$ \\
\end{tabular}} & \multirow{2}{*}{$\begin{array}{l}\text { Estimated air } \\
\text { kerma rate due to } \\
\text { gamma rays from } \\
{ }^{134} \mathrm{Cs} \text { and }{ }^{137} \mathrm{Cs} \\
\text { at measuring date } \\
\left(\mu \mathrm{Gy} \mathrm{h}{ }^{-1}\right)\end{array}$} \\
\hline & & & ${ }^{134} \mathrm{Cs}$ & ${ }^{137} \mathrm{Cs}$ & \\
\hline $\begin{array}{l}\text { Ohkuma- } \\
\text { town, } \\
\text { Chuodai }\end{array}$ & \begin{tabular}{|l|}
$37: 25: 26 \mathrm{~N}$ \\
$141: 00: 08 \mathrm{E}$
\end{tabular} & $2.7, \mathrm{~W}$ & $(1.10 \pm 0.02) \times 10^{4}$ & $(1.05 \pm 0.03) \times 10^{4}$ & $35.8 \pm 0.5$ \\
\hline $\begin{array}{l}\text { Ohkuma- } \\
\text { town, } \\
\text { Ohno } \\
\text { station }\end{array}$ & \begin{tabular}{|l|}
$37: 24: 32 \mathrm{~N}$ \\
$140: 59: 07 \mathrm{E}$
\end{tabular} & $\begin{array}{l}4.4, \\
\text { WSW }\end{array}$ & $(3.29 \pm 0.24) \times 10^{3}$ & $(3.37 \pm 0.08) \times 10^{3}$ & $10.7 \pm 0.5$ \\
\hline $\begin{array}{l}\text { Futaba- } \\
\text { town, } \\
\text { Kami- } \\
\text { hatori }\end{array}$ & $\begin{array}{l}37: 27: 25 \mathrm{~N} \\
140: 59: 22 \mathrm{E}\end{array}$ & $\begin{array}{l}5.6 \\
\text { NW }\end{array}$ & $(1.89 \pm 0.13) \times 10^{3}$ & $(1.88 \pm 0.05) \times 10^{3}$ & $6.11 \pm 0.26$ \\
\hline
\end{tabular}


Table 11.3 Comparison of measured dose equivalent rate and estimated air kerma rate in terms of various methods

\begin{tabular}{|c|c|c|c|c|c|c|}
\hline Location & $\begin{array}{l}\text { Coordinate } \\
\text { of location }\end{array}$ & $\begin{array}{l}\text { Distance } \\
\text { from FDNPS } \\
(\mathrm{km})\end{array}$ & 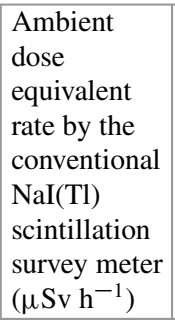 & $\begin{array}{l}\text { Estimated air } \\
\text { kerma rate } \\
\text { due to }{ }^{134} \mathrm{Cs} \\
\text { and }{ }^{137} \mathrm{Cs} \text { at } \\
\text { measuring } \\
\text { date } \\
\left(\mu \mathrm{Gy} \mathrm{h}{ }^{-1}\right)\end{array}$ & $\begin{array}{l}\text { Estimated } \\
\text { air kerma } \\
\text { rate by the } \\
\text { stripping } \\
\text { method } \\
\left(\mu \mathrm{Gy} \mathrm{h}^{-1}\right)\end{array}$ & $\begin{array}{l}\text { Estimated air } \\
\text { kerma rate } \\
\text { by the } G(E) \\
\text { function } \\
\text { method } \\
\left(\mu G y h^{-1}\right)\end{array}$ \\
\hline $\begin{array}{l}\text { Ohkuma- } \\
\text { town, } \\
\text { Chuodai }\end{array}$ & $\begin{array}{l}37: 25: 26 \mathrm{~N} \\
141: 00: 08 \mathrm{E}\end{array}$ & $2.7, \mathrm{~W}$ & $45.3 \pm 0.4$ & $35.8 \pm 0.5$ & 33.2 & 37.1 \\
\hline $\begin{array}{l}\text { Ohkuma- } \\
\text { town, } \\
\text { Ohno } \\
\text { station }\end{array}$ & $\begin{array}{l}37: 24: 32 \mathrm{~N} \\
140: 59: 07 \mathrm{E}\end{array}$ & 4.4, WSW & $12.9 \pm 0.1$ & $10.7 \pm 0.5$ & 9.35 & 14.1 \\
\hline $\begin{array}{l}\text { Futaba- } \\
\text { town, } \\
\text { Kamiha- } \\
\text { tori }\end{array}$ & $\begin{array}{l}37: 27: 25 \mathrm{~N} \\
140: 59: 22 \mathrm{E}\end{array}$ & 5.6, NW & $1.63 \pm 0.02$ & $6.11 \pm 0.26$ & 2.17 & 3.29 \\
\hline
\end{tabular}

Table 11.3 shows the comparison of air kerma rates, $\dot{K}_{\text {air }}\left(\mu \mathrm{Gy} \mathrm{h} \mathrm{h}^{-1}\right)$, estimated from measured surface contamination densities on soil and in terms of the stripping and $\mathrm{G}(\mathrm{E})$ function methods. Measured ambient dose equivalent rates, $\dot{H}^{*}(10)$ $\left(\mu \mathrm{Sv} \mathrm{h}{ }^{-1}\right)$, at the same measurement points were also listed. All results were corrected at measuring date (28 May 2013). Results obtained in high-dose rate areas were considered to be identical within $6 \%$. However, results obtained in lower-dose rate region have large discrepancy, particularly between air kerma rate estimated from surface deposition densities on soil and others. This might be caused by improper setting of relaxation mass, $\beta$, for determining the surface deposition densities on soil. On the other hand, air kerma rates estimated by the stripping method and the $\mathrm{G}(\mathrm{E})$ function method might reproduce actual air kerma rate, comparing with ambient dose equivalent rate obtained by the $\mathrm{NaI}(\mathrm{Tl})$ survey meter. Further investigation should be required for more accurate estimation of dose rate at measurement places.

\subsection{Summary}

A light-weight, easy-to-handle and cooling-free CdZnTe (CZT) semiconductor detector whose crystal has dimensions of 1 cubic $\mathrm{cm}$ was applied to the rapid and simple in situ environmental radioactivity measurement in deeply contaminated areas in Fukushima region in 2013. Even in high-dose rate areas more than a couple 
of tenth $\mu \mathrm{Sv} \mathrm{h}^{-1}$, the CZT detector allowed to obtain the proper and fine pulse height spectrum, which is clearly distinguished peaks from gamma rays due to ${ }^{134} \mathrm{Cs}$ and ${ }^{137} \mathrm{Cs}$. Results of deposition density on soil for ${ }^{134} \mathrm{Cs}$ and ${ }^{137} \mathrm{Cs}$ derived from net peak areas by the CZT detector were evaluated to be between $1.9 \times 10^{3}$ and $1.1 \times 10^{4} \mathrm{kBq} \mathrm{m}^{-2}$ for each radio-cesium. They were also found to be consistent, comparing with those measured by the Japanese government and obtained in other literature. Air kerma rates were estimated using the same pulse height spectra by the stripping and the $\mathrm{G}(\mathrm{E})$ function methods. Estimated results showed almost the same values as obtained by the $\mathrm{NaI}(\mathrm{Tl})$ scintillation survey meter, considering the differences of dosimetric quantities.

Throughout performance tests done in this study, the CZT detector has poor energy resolution and less sensitivity to energetic gamma rays with energies above $1500 \mathrm{keV}$, namely, gamma rays from ${ }^{40} \mathrm{~K}$. However, this means the CZT detector could eliminate interferences, when used in areas whose dose rates are more than a couple of tenth $\mu \mathrm{Sv} \mathrm{h}^{-1}$ due to contamination by radio-cesiums. The field monitoring test showed the CZT detector is easy to use and helps shorten staying time at measurement points whose dose rates exceed several tenth $\mu \mathrm{Sv} \mathrm{h}^{-1}$. The study also clearly indicates that the CZT detector is one promising candidate for the detector to be used for checking the effect of decontamination works and for long-term monitoring in heavily contaminated areas, in order to accelerate implementations of decontamination and remediation works in "difficult-to-return zone."

Acknowledgements The authors thank all staff members of Hotel Matsushimaya Ryokan in Fukushima-city for their heart-warming hospitality and continuing support for our research project.

Funding This research work was supported by the KUR Research Program for Scientific Basis of Nuclear Safety.

Open Access This chapter is distributed under the terms of the Creative Commons Attribution Noncommercial License, which permits any noncommercial use, distribution, and reproduction in any medium, provided the original author(s) and source are credited.

\section{References}

1. Beck HL, DeCampo J, Gogolak C (1972) In situ Ge(Li) and NaI(Tl) gamma-ray spectrometry for the measurement of environmental radiation, USAEC report HASL-258. USAEC, New York

2. International Commission on Radiation Units and Measurements (1994) Gamma-ray spectrometry in the environment, ICRU report 53. ICRU, Bethesda

3. Shibahara Y, Kubota T, Fujii T et al (2014) Analysis of cesium isotope compositions in environmental samples by thermal ionization mass spectrometry -1 . A preliminary study for source analysis of radioactive contamination in Fukushima prefecture. J Nucl Sci Technol 51(5):575-579

4. Kowatari M, Kubota T, Shibahara Y et al (2015) Application of a CZT detector to in situ environmental radioactivity measurement in the Fukushima area. Radiat Prot Dosimetry. doi:10.1093/rpd/ncv277 
5. Kurosawa T, Iwase H, Saito $\mathrm{H}$ et al (2014) Field photon energy spectra in Fukushima after the nuclear accident. J Nucl Sci Technol 51(5):730-734

6. Moriuchi S, Miyanaga I (1966) A method of pulse height weighting using the discrimination bias modulation. Health Phys 12(10):1481-1487

7. International Commission on Radiological Protection (ICRP) (1997) Conversion coefficients for use in radiological protection against external radiation, ICRP publication 74 Ann. ICRP 27(4). Pergamon Press, London/New York 